\title{
Discursos conciliadores no debate sobre ação afirmativa no Ensino Superior
}

\author{
Angela Randolpho Paiva
}

O debate sobre ação afirmativa no ensino superior se intensificou no final da década de 1990, quando propostas de projeto de lei tramitavam na Assembleia Legislativa de estados brasileiros, quando a ação dos movimentos negros passou a enfatizar o acesso ao ensino superior, e ainda quando análises de agências governamentais e acadêmicas mostravam o ciclo perverso existente no sistema educacional brasileiro no que diz respeito ao acesso às universidades públicas. Afinal, cerca de $80 \%$ de suas vagas eram preenchidas por aqueles $20 \%$ que tinham capital econômico para fazer o percurso escolar até o Ensino Médio nas boas escolas do sistema privado de ensino, enquanto os $80 \%$ que cursavam as escolas públicas conseguiam as $20 \%$ restantes.

É uma equação evidentemente perversa, mas a ideologia do mérito, muito forte nas relações sociais brasileiras, naturalizava tal equação. Afinal, tinham acesso ao ensino superior aqueles que tinham a "competência" de passar no vestibular, sistema nacional de entrada para as melhores universidades públicas do país, sistema aceito sem discussão por todas as camadas sociais. Mas este funil para a entrada no ensino superior também sempre teve uma cor: segundo dados do Censo do IBGE de 2000, havia $8 \%$ de alunos nas universidades brasileiras, $12 \%$ de brancos e $4 \%$ de pretos e pardos. ${ }^{1}$ Tal correlação havia se mantido a mesma do Censo de 1990 (média de 4\%, $2 \%$ de negros e $8 \%$ de brancos) e depois a mesma do Censo de 2010. O acesso aumentava, mas a proporção era a mesma, como se fosse uma linha de trem. Dessa forma, o debate sobre ação afirmativa (AA) no ensino superior veio questionar não só a idéia forte da meritocracia, como também a existência da profunda desigualdade racial no sistema de ensino superior brasileiro. Foi uma luta iniciada pelos movimentos negros no final da década de 1990 e teve sua consolidação nos primeiros anos da década de 2000.

O objetivo da presente análise é contextualizar a discussão sobre AA, ressaltando alguns fatores que levaram a questão da desigualdade racial no ensino superior aos espaços discursivos da esfera pública. Vão ser destacados cinco aspectos: a) o momento da redemocratização do país, quando surgiram demandas por direitos de vários movimentos sociais e, no caso em tela, os movimentos negros; $b$ ) a gênese da ação coletiva no que concerne à ação dos movimentos negros no final da década de 90, cuja confluência de alguns fatores foi fundamental para o consenso alcançado em torno

\footnotetext{
${ }^{1}$ A classificação racial do Censo brasileiro realizado pelo IBGE a cada 10 anos, é distribuída entre as categorias branco, preto, amarelo, pardo e indígena. A categoria negra é usada pelos movimentos negros englobando pretos e pardos. Na presente análise será usada a categoria negra, exceto quando estiver referida ao Censo.
} 
da AA; c) o debate intenso nos espaços públicos, em especial na mídia e universidades, sobre a "cota para negros"; d) o processo que se iniciou nas universidades públicas estaduais e federais a partir de 2002, que vai ser mostrado com base na pesquisa realizada na PUC-Rio - "Monitoramento e Acompanhamento da Implantação das Políticas de Ação Afirmativa nas Universidades Públicas Brasileiras" - feita ao longo de cinco anos, de 2006 a 2011 com financiamento da FINEP; e) por último, com base nesta pesquisa, vai ser mostrado o discurso conciliador que foi levado a cabo nos conselhos universitários das principais universidades do país, quando "cota social" prevaleceu em detrimento da "cota racial", o que mostra como as desigualdades raciais do país são difíceis de serem não só discutidas, mas também como é forte a ideia de que raça está contida na classe.

Para isso, torna-se importante entender o contexto, o processo de ação coletiva, as estratégias, os atores e os marcos interpretativos (frames) utilizados na demanda ao acesso superior. Afinal, em um intervalo de dez anos, mais de $70 \%$ das universidades públicas brasileiras haviam adotado algum tipo de ação afirmativa.

\section{Contextualizando o debate}

Desde os anos 1980, quando se inicia o processo de redemocratização do país, vários movimentos sociais trazem para o debate público as profundas desigualdades persistentes do acordo social brasileiro. Eram movimentos pedindo o reconhecimento dos direitos dos povos nativos, a redistribuição fundiária, o compromisso constitucional acerca das condições de moradia das periferias e favelas, o fim das desigualdades raciais, dentre tantas outras questões que pautaram o período da Constituinte, e quando várias delas foram incorporadas na nova Constituição de 1988. Desde então, foram apresentados projetos de lei acerca de todas as formas de desigualdade, numa chave que combina tanto a redistribuição quanto o reconhecimento (Fraser, 2003). No que tange à desigualdade racial, vários projetos de lei que visavam à penalidade de atos de discriminação e insulto raciais foram apresentados desde a década de 1980, em especial a Lei Caó (Lei 7716/89), mas foi a Lei Paim (Lei 9459/97) a mais contundente: definiu crimes resultantes de preconceito de raça ou de cor como crime inafiançável. No que se refere à ação afirmativa nas universidades e no mercado de trabalho, vários projetos surgiram em legislativos estaduais ao longo da década de 1990, não sendo nenhum aprovado. Somente na década de 2000 começaram a ser implantados, como vai ser analisado adiante. ${ }^{2}$

Nessa mesma época se intensifica a ação dos vários movimentos negros que haviam se formado em uma frente de ação coletiva, em 1978, no que se chamou de

\footnotetext{
${ }^{2}$ Ver as análises de Joaze Bernadino (2002) e Rosana Heringer (2004) para as discussões em curso na década de 90, tanto no Legislativo quanto no Executivo. Ver ainda Edward Telles (2003) para excelente análise do racismo à brasileira.
}

R 
Movimento Negro Unificado - MNU, com pauta convergente para a denúncia de racismo no Brasil, além da demanda de acesso à educação e justiça. E se nos anos 80 o MNU trazia a demanda para ampliação do acesso à educação da população negra em geral, no final dos anos 90, depois de mais de uma década de ação coletiva mais eficaz com a vigência da nova Constituição de 1988, a demanda passou a ser por acesso ao ensino superior. Pode-se perguntar, assim, quais fatores levaram a tal demanda?

Primeiramente, é preciso lembrar que a década de 1990 representou uma constante tensão entre os princípios constitucionais que se expandiram na Carta de 88, que previa até a fruição de direitos coletivos no caso dos quilombolas e povos indígenas, e uma cultura política cujas práticas haviam pautado a esfera pública desde sempre, numa coexistência de novas práticas de participação da sociedade civil com as velhas práticas políticas patrimonialistas e clientelistas. (Avritzer,1995). Porque o ideário de liberdade e igualdade prescrito em todas as versões constitucionais ao longo do século XX sempre foram prescrições formais que, um dia, se realizaria no país do futuro. Portanto, uma nova idéia de cidadania começou a ser forjada pelos movimentos sociais que se organizaram com a redemocratização, desde aqueles que pediam redistribuição dos bens da nação, como os movimentos de luta pela terra ou pela moradia, como aqueles que se construíram em torno de identidades novas, como o movimento ambientalista, LGBT ou dos deficientes físicos. Outros movimentos, como os de mulheres e de negros, denunciavam as desigualdades materiais que foram provocadas pelo não reconhecimento sistemático de seus direitos como ser humano de igual valor. Na chave de Nancy Fraser (2003) haveria nesse último grupo tanto a demanda por redistribuição, quanto por reconhecimento. ${ }^{3}$

Um segundo aspecto crucial foi o protagonismo da sociedade civil que se articulava em novas formas independentes do Estado. Desde o final da década de 1970, ONGs, movimentos sociais e associações saíram em defesa dos direitos civis e políticos, suprimidos com a ditadura militar, e dos direitos sociais. Na esteira desse processo, no final da década de 1980, associações e movimentos cobravam a realização efetiva dos princípios prescritos na Constituição, não mais os direitos formais que deveriam ser realizados, um dia, quando o desenvolvimento do país alcançaria a todos (outra ideologia!) mas a fruição efetiva dos direitos civis, políticos, sociais e culturais. No retorno à democracia, eram demandados os direitos substantivos, quando o Estado deveria ter novo papel para o reconhecimento de grupos até então subalternizados e para a redistribuição dos bens materiais, em um país que detinha uma das maiores concentração de renda do planeta.

\footnotetext{
${ }^{3}$ Esta é uma discussão muito rica para a análise dos conflitos sociais, especialmente a discussão travada entre Nancy Fraser e Axel Honneth no livro Redistribution or Recognition. A teoria do reconhecimento trouxe grande aporte conceitual a partir do final da década de 1980 para a construção de uma teoria crítica, mas devido ao escopo da presente análise, serão trazidos apenas aqueles conceitos que fortalecem a argumentação desenvolvida aqui.
} 
Foi uma equação difícil de ser realizada: juntamente com as novas demandas trazidas com a redemocratização, houve constante pressão econômica por uma menor presença do Estado. A velha equação entre a desigualdade produzida pelo sistema capitalista e a igualdade pedida para fruição dos direitos sociais, tão bem analisada por Bendix (1996) nos países centrais acerca do modelo de welfare state pensado no pós-guerra, não podia mais ser realizada, no momento em que o Estado tem de cumprir com metas que afetam profundamente o modelo social pensado então. É outra equação perversa para o Estado brasileiro: de um lado, há demandas pela fruição substantiva de direitos dos mais diversos grupos invisibilizados ou subalternizados, e, por outro, há a impossibilidade histórica de não ser capaz da realização de um estado de bem-estar social mínimo, impossibilitado economicamente de contemplar tais demandas. ${ }^{4}$

E isso leva ao terceiro aspecto: a mudança no que se entende sobre a idéia de direitos humanos, que passa de uma idéia de direitos abstrata para a demanda pela fruição substantiva dos direitos humanos, quando os tradicionais mecanismos de manutenção das desigualdades duráveis, como definiu Tilly (1999) os marcadores de classe, raça e gênero, ou seja, aquelas hierarquias sociais consolidadas por relações estruturais que perpassam gerações e se transformam em marcações excludentes, foram postas em cheque pelos vários movimentos sociais que chegaram para pedir uma nova idéia de cidadania, cujo marco está baseado na universalização dos direitos mais básicos e no atendimento a novas demandas específicas que combinem a igualdade que requer a fruição universalizada dos direitos de cidadania, com a diferença, no atendimento das novas identidades construídas, como bem analisou Iris Young (1995).

Tal confluência de fatores está presente na ação dos movimentos negros que se fortaleceram nos anos 80 e 90 e que giram não apenas em torno de novas formas de organização coletiva, mas também de demandas efetivas ao Estado e de um ator social que surge pautando a esfera pública. Denunciavam a persistência da discriminação racial, num país em que a miscigenação foi sempre exaltada e a raça negada; denunciavam também a democracia racial, cujo imaginário social negava que houvesse desigualdade racial, pois a desigualdade social seria resolvida - para brancos e negros - com o desenvolvimento futuro, ideário compartilhado por toda a nação. Denunciavam ainda a desigualdade de oportunidades resultante do processo histórico da desigualdade racial persistente. Afinal, aos negros não lhes couberam políticas públicas ao final do sistema escravocrata para sua integração social; muito pelo contrário, foram deixados à própria sorte em um momento em que se incentivava fortemente a imigração européia para embranquecer o pais.

\footnotetext{
${ }^{4}$ Para os dilemas postos na nova configuração global que resultou em novas tensões e na "erosão da cidadania", ver Turner, (2001). Para a análise da "confluência perversa" no contexto brasileiro, ver Evelina Dagnino (2003)
} 


\section{Gênese da ação coletiva em torno da AA}

Foi nesse momento de denúncia das diversas desigualdades persistentes no país que o movimento negro se unificou e chegou ao consenso de que a demanda da luta pela discriminação racial deveria ser colocada no ensino superior para acelerar o processo pela igualdade racial. No final dos anos 90, década rica no protagonismo da sociedade civil aliado a governos democráticos mais porosos às demandas que estavam sendo colocadas na esfera pública, havia projetos de lei nas assembleias legislativas ou no congresso que traziam a responsabilidade do Estado para ação mais efetiva como remédio para as diversas formas da desigualdade racial. Assim, as ideologias do desenvolvimento, da democracia racial e do mérito, tão poderosas para a aquiescência da população negra e pobre por várias décadas, passaram a ser questionadas em debates públicos. ${ }^{5}$

Mas cabe perguntar como tal consenso foi atingido? Foram vários fatores e aqui será enfatizada a confluência de três deles que contribuíram para a efetivação de uma ação coletiva concreta, independentemente das discussões no legislativo, no executivo ou no judiciário: primeiramente, a preparação brasileira para a Conferência Internacional contra o Racismo, a Discriminação, a Xenofobia e a Intolerância, da ONU, realizada em Durban, na África do Sul, em 2003, suscitou uma série de debates e reuniões sobre desigualdade racial no Brasil, que teve, como um dos principais consensos alcançado, a ideia de que a ação afirmativa no ensino superior era estratégica para que os caminhos pela igualdade racial fossem abreviados (Alberti \& Pereira, 2007; Telles, 2003). Pode-se dizer que as preparatórias para Durban representaram o espaço discursivo pensado por Habermas (1984), quando novas questões em torno da desigualdade racial foram trazidas para a esfera pública. Para usar a análise de Fraser (1997), foi o momento em que o espaço contra-público não hegemônico dos movimentos negros se transformou em "públicos fortes" ao chegar à esfera pública mais ampla. Foi um processo lento de gestação, mas os diversos atores foram capazes de construir outro marco interpretativo (frames) sobre justiça, direitos e equidade para manifestar um confronto inédito - agora em torno da questão racial e suas várias formas de discriminação e invisibilização - e pautar demandas específicas.

Mas não se deve superdimensionar Durban. Afinal, a ação dos movimentos negros era intensa desde a década de 1980. Um segundo fator importante na década de 90 foi a produção de dados sobre a desigualdade racial brasileira. Estudos do IPEA

\footnotetext{
${ }^{5}$ Não se pode esquecer que o debate sobre a desigualdade racial começou ainda no governo de Fernando Henrique Cardoso, que reconheceu a existência do racismo em seminário realizado em Brasília em 1996, iniciativa do recémcriado Plano Nacional dos Direitos Humanos. Esse seminário se realizou um ano depois da Marcha de 300 anos de Zumbi dos Palmares em Brasília. Ainda no governo FHC, houve tímidas iniciativas de Ação afirmativa em alguns ministérios, mas foram ações residuais. Para os principais temas discutidos naquele seminário, ação afirmativa, desigualdade racial, racismo e multiculturalismo, ver o livro organizado por Jessé Souza (1997), Multiculturalismo e racismo.
}

RASILIANA- Journal for Brazilian Studies. Vol. 6, n.2 (October, 2018). ISSN 2245-4373. 
e IBGE mostravam no final daquela década que a desigualdade brasileira tinha cor e que esta se traduzia de forma dramática no sistema educacional de ensino brasileiro, em geral, e no acesso à universidade, em particular. E se antes os estudos sobre as desigualdades raciais eram feitos por acadêmicos (Florestan Fernandes, final da década de 50; Carlos Hasenbalg e Nelson do Valle e Silva nos anos 70), ou pelos precursores/acadêmicos da militância negra (Abdias do Nascimento, década de 50; Lélia Gonzalez, anos 70), os estudos provenientes de órgãos do Estado provocaram maior divulgação em um período já democrático, momento em que os governos passaram a ser mais porosos a tais demandas. ${ }^{6}$ Dessa forma, os atores dos movimentos negros puderam contar com evidências contundentes sobre a desigualdade racial, agora focada no ensino superior.

Um terceiro fato fundamental foi a ação dos vários movimentos negros, seja a daqueles que já estavam na universidade e haviam criado desde a década de 1980 os Núcleos de Estudos Afro-Brasileiros nas universidades (NEABs), seja com a criação dos Pré-Vestibulares para Negros e Carentes - PVNC - que na década de 90 contribuíram para que alunos provenientes das escolas públicas pudessem estar qualificados para o vestibular. ${ }^{7}$ Juntamente com a chegada de mais alunos no ensino médio, estudantes da periferia e de favelas de todas as cores começaram a vislumbrar a possibilidade de cursar uma universidade. Havia ainda a ação individual de diversos professores (negros ou não) que levavam a discussão sobre ação afirmativa para os Conselhos Universitários. Não cabe aqui fazer a análise pormenorizada dos vários atores que se organizavam, mas tanto os NEABs quanto os PVNCs, além daqueles professores que questionavam a existência de uma universidade pública que atendia a um percentual tão grande de brancos, foram decisivos para o que viria na década de 2000.

\section{Debate na esfera pública e a construção de novos frames}

A década de 2000 pode ser interpretada como a década do debate da questão racial e da ação afirmativa no ensino superior: antigas ideias fortes da nossa construção social passaram a ser questionadas pelos militantes dos movimentos negros, pela ação de grupos da sociedade civil - ONGs, coletivos, acadêmicos e gestores das universidades - que trouxeram novos marcos interpretativos para o entendimento da desigualdade

\footnotetext{
${ }^{6}$ Ver, por exemplo, o texto de Ricardo Henriques (2001) produzido no IPEA, em que mostra de forma contundente a desigualdade ao acesso ao ensino superior pelo recorte da raça. Assim como a intersecção entre raça e gênero. Ver ainda a análise de Antonio Sérgio Guimarães (1997) sobre racismo e anti-racismo feita na década de 90, que produziu forte impacto os meios acadêmicos.

${ }^{7}$ Os pré-vestibulares que surgiram ao longo da década de 1990 para jovens e carentes, realizados em escolas e paróquias, resultaram em oportunidades novas para jovens poderem se qualificar para o vestibular. Ver Renato Emerson dos Santos (2003) para o relato das tensões dos vestibulares comunitários, em especial entre PVNCs e Educafro. Frei Davi dos Santos, fundador do último, foi sempre incansável na luta pelo acesso dos negros ao ensino superior.
}

RASILIANA-Journal for Brazilian Studies. Vol. 6, n.2 (October, 2018). ISSN 2245-4373. 
racial brasileira. Os novos frames tinham como palavras-chave a desigualdade racial nas universidades públicas, a defesa pela diversidade nos campi brasileiros com a entrada de alunos negros e pobres, e ainda a justiça devida a grupos historicamente excluídos. Os dados do IPEA, do IBGE, assim como o Relatório Anual das Desigualdades Raciais do LAESER (Paixão e Carvano, 2008), ou as pesquisas desenvolvidas pelo Grupo de Estudos Multidisciplinares de Ação Afirmativa (GEMAA), coordenado por João Feres Jr., dentre vários outros, revelavam um quadro de desigualdade racial contundente: a população que se autodeclarava preta e parda no Censo de 2010 compreendia mais da metade da população brasileira, enquanto as taxas de frequência escolar de brancos era três vezes maior $(24,3 \%)$ do que a de pretos e pardos $(8 \%){ }^{8}$

Mas a questão da AA nas universidades públicas não foi uma discussão fácil nos meios acadêmicos e no debate público. Seus primeiros defensores mostravam como a universidade pública, gratuita, não cumpria sua função social de atender aos diversos grupos sociais da sociedade brasileira; mostravam como os mecanismos de entrada na universidade pelo vestibular eram perversos ao privilegiarem aqueles com condições econômicas para o treinamento para o "êxito" acadêmico de apenas um instrumento de aferição - o vestibular; trouxeram ainda a difícil discussão sobre raça, ideia que feria a ideologia da democracia racial brasileira. Surgiu assim intenso debate a respeito da existência ou não de raça no mundo contemporâneo, conceito negado pela biologia e por grande número de cientistas sociais. Na verdade, este foi um dos pontos centrais no debate ocorrido ao longo da década de 2000 para a construção de um novo esquema de argumentos (frame): por um lado, foi ressaltada a construção social da raça que se contrapusesse à tão exaltada celebração das três raças brasileiras, e por outro, havia a negação da raça simplesmente, o que inviabilizava políticas baseadas na classificação racial. E a ideia de cotas para negros perpassou o debate naquele momento. ${ }^{9}$

Foi um momento de muita discussão. Aqueles que eram contrários às "cotas para negros", o faziam por quatro razões principais: a) cotas raciais feririam o princípio republicano da igualdade, introduzindo uma divisão racial inexistente no pais; b) as cotas acionariam o racismo numa sociedade que não é orientada pela questão de raça; c) as cotas iriam contra a luta universal pelos direitos sociais, pois era direcionada a um grupo específico; d) por último, havia o forte apelo à concepção mesma de nação brasileira, cuja construção se deu na defesa da "diversidade" e pela inexistência de

\footnotetext{
${ }^{8}$ Ver Petrucelli (2010) para a análise histórica dos censos brasileiros sobre a classificação racial. O autor lembra ainda a famosa pesquisa sobre a classificação racial dos brasileiros, quando foram encontradas 143 cores distintas, badalada nos principais meios de comunicação do país, mas praticamente todo o universo da pesquisa se concentrava nas cinco classificações do IBGE, além da categoria moreno.

${ }^{9}$ A palavra "cotas"é a que prevalece nas discussões levadas a cabo durante a década de 2000, mas é um termo incompleto para designar as políticas pensadas pelas universidades públicas na década de 2000 , como será visto adiante. Assim, vai ser defendido aqui o uso de ação afirmativa (AA) e não cotas para descrever o processo realizado pelas universidades públicas.
} 
discriminação racial. Esses quatro argumentos ainda eram complementados com a ideia de que o remédio para as desigualdades raciais deveria começar por políticas que melhorassem o sistema de ensino público na base, no ensino fundamental.

Para aqueles que eram a favor, os argumentos principais elencados foram cinco: a) a necessidade de políticas mais rápidas que encurtassem o fosso da desigualdade racial; b) a denúncia da exclusão sistêmica da população negra como resultado tanto do legado de uma sociedade escravocrata quanto da ausência de políticas públicas de integração social; c) a necessidade de reparação diante das estruturas (raciais) desiguais; d) a defesa da ação afirmativa na luta por uma universidade pública mais representativa da composição racial brasileira; e) e, por último, o debate tratava das formas sutis de racismo e das formas eficientes de mecanismos de reprodução da desigualdade no acesso à educação, e em especial à universidade. ${ }^{10}$

Percebe-se assim que este era o cenário suscitado pelas primeiras políticas de AA no ensino superior. Com a breve síntese feita acima, pode-se entender que os argumentos daqueles que eram contrários às cotas estavam baseados em princípios que reportavam à ideia de nação, à diversidade, ou aos direitos na sua concepção formal e abstrata, enquanto o discurso dos defensores das AA traduzia a defesa por uma democracia substantiva e o reconhecimento de um contexto de injustiça oriundo tanto do legado não resolvido pelo regime escravocrata, quanto da falta de políticas públicas, especialmente as educacionais que pudessem vir a remediar as desigualdades iniciais do contrato social. Interessante notar que a ideia de república trazia duas versões distintas: enquanto para os contrários às AA república se traduz na defesa dos princípios norteadores da liberdade abstrata dos cidadãos brasileiros, para os defensores das AA a república deveria fazer cumprir esse ideal com a promoção efetiva da igualdade. Para que esses argumentos pudessem conquistar a esfera pública, houve, assim, a necessidade de construção de novos frames, marcos interpretativos, que traduzissem um novo esquema de interpretação dessas desigualdades.

A teoria dos movimentos sociais ressalta a importância da construção de novos marcos interpretativos para a emergência de um movimento social e buscaram em Goffman uma importante fonte para a análise dos novos discursos. Goffman elaborou o conceito de frame analysis para analisar as interações subjetivas nos contatos face a face. Para Goffman (1977), são esquemas que traduzem novos argumentos, a partir da ênfase de novas experiências, valores, fatos, evidências, que criam visões de mundo inovadoras para traduzirem visões de mundo distintas da então predominante. Os teóricos dos movimentos sociais contemporâneos desenvolveram o conceito de Goffman para a ação coletiva. Sidney Tarrow (1998) lembra ainda a importante contribuição de Bert Klandermans que ressaltou que a passagem de questões sociais para frames de ação coletiva não acontece espontaneamente: "It is a process in which

${ }^{10}$ Os conceitos-chave elencados acima sintetizam os dois manifestos escritos por acadêmicos, personalidades da sociedade civil e militantes, em 2004, quando se posicionaram contra e a favor de "cotas para negros. 
social actors, media, and members of a society jointly interpret, define and redefine states of affairs" (apud Tarrow, p.110)

$\mathrm{Na}$ análise dos movimentos sociais contemporâneos é um conceito de grande validade heurística para a compreensão dos novos esquemas interpretativos que são construídos e que possuem significado para a emergência de qualquer ação coletiva. Assim sendo, os frames construídos para questionar os padrões de injustiça da universidade pública brasileira significaram nova leitura de uma situação não antes questionada. Como vai ser visto adiante, há uma nova interpretação do que seja justiça social, desigualdade nas relações raciais e o caráter elitista da universidade pública brasileira.

É uma nova racionalização do que Habermas chamou de mundo da vida, no momento em que indivíduos tomam consciência de situações de injustiça, opressão ou ainda subalternidade. Nesses novos espaços discursivos, para seguir com Habermas, pode-se chegar à construção de frames, novas arenas discursivas que vão desafiar o discurso predominante, ou seja, decolonizar o mundo da vida. (Habermas, 1987), resultado de processo longo em que são pensadas novas matrizes discursivas e ações estratégicas inovadoras. ${ }^{11}$ Trata-se da radicalização da ideia de liberdade, agora traduzida em autonomia, e de igualdade, traduzida em justiça (Gohn, 2010), ideias estas que traduzem novo significado do que seja cidadania substantiva. Foi nesse contexto que surgiu a demanda por ação afirmativa no ensino superior.

\section{Ação afirmativa nas universidades públicas brasileiras}

Viu-se anteriormente que o pedido de AA nas universidades públicas brasileiras foi uma demanda específica do consenso alcançado pelos vários movimentos negros. Viuse também que tal ideia já tramitava em assembleias estaduais desde o final da década de 1990. E viu-se ainda que não poderia ser tarefa fácil em um país em que a "raça", quando anunciada, era para lembrar sua unidade nacional, como foi reforçada no período de Getúlio Vargas. Afinal, estavam sendo questionados valores caros ao imaginário social brasileiro.

A implantação de políticas de AA no ensino superior pode ser traduzida como a radicalização da ideia de cidadania. É o momento em que se questiona a "neutralidade estatal", como define Joaquim Barbosa o cenário sociopolítico brasileiro que convive de maneira ambígua com o ideário de direitos humanos em contexto de extrema desigualdade. O novo frame que ganha força é o questionamento da equação perversa do sistema de admissão nas universidades públicas brasileiras.

\footnotetext{
${ }^{11}$ Ver a análise exaustiva de Cohen e Arato (2000) sobre o conceito de sociedade civil na teoria social, que apontam a importância do conceito habermasiano de mundo da vida para novas formas de associação quando racionalizadas. Para uma excelente discussão sobre a racionalização do mundo da vida, essencial para o surgimento de novos movimentos sociais, ver Sérgio Costa (2002)
} 
Depois de quinze anos de intensos debates e adoção de políticas de AA pelas universidades federais e estaduais do país, a ideia de AA em si já está bastante assimilada, mesmo entre aqueles que a rejeitavam inicialmente. Houve um processo pedagógico na construção de políticas de AA desde 2002 que terminou por ser bastante aceito pela opinião pública brasileira. Em nenhum momento se questionou a reserva de vagas para as populações indígenas e hoje é aceita a ideia de AA para escolas públicas. Como a pesquisa apresentada a seguir vai mostrar, foi a "cota social", como os entrevistados chamaram a AA para alunos oriundos das escolas públicas, que acabou prevalecendo sobre a "cota racial". Mas foi esta última que originou todo o debate sobre AA no ensino superior. Além do mais, não houve nenhum movimento social de estudantes das escolas públicas para o ingresso nas universidades públicas.

A pesquisa "Monitoramento e Acompanhamento das Políticas de Ação Afirmativa nas Universidades Públicas Brasileiras" foi realizada entre 2006 e 2011, com financiamento da FINEP, contando com pesquisa de campo em 20 universidades das cinco regiões do país em duas etapas: a primeira entre 2006 e 2008, quando foram visitadas 10 universidades, e a segunda entre 2009 e 2011, outras 10 foram pesquisadas. O principal critério de seleção das universidades para a pesquisa de campo era o tempo de existência de políticas AA efetivas, que tinham de estar vigentes há pelo menos dois anos. Foram entrevistados 57 gestores que estavam à frente da implantação das medidas, que eram responsáveis pelo atendimento aos alunos, e lideranças dos NEABs. Houve vários consensos entre os entrevistados que serão sintetizados a seguir. 12

O período de realização da pesquisa, de plena expansão da adoção de AA, nos possibilitou compreender o processo em curso nas universidades públicas estaduais e federais. Para o que interessa na presente análise, foi possível verificar o que se falava acima sobre os frames que estavam sendo construídos no campus: muita discussão nos Conselhos Universitários, palestras de acadêmicos com números acerca da subrepresentação negra nas universidades; ação ativa dos NEABs para a formatação dos novos argumentos, além do apoio dos reitores das universidades pioneiras na adoção de AA.

Quando tudo começou? Em 2002 foi implantado o acréscimo de vaga para populações indígenas de cinco universidades estaduais do Paraná; em 2003 surgem as "cotas" para negros, alunos de escolas públicas e deficientes nas universidades estaduais do Rio de Janeiro (UERJ e UENF) e Bahia. (UNEB); em 2004 surge a primeira universidade federal, UnB, com cotas somente para negros (motivo de grande

\footnotetext{
${ }^{12}$ Os resultados da pesquisa estão publicados nos livros Entre dados e fatos: Ação afirmativa nas universidades públicas brasileiras e Ação Afirmativa em Questão: Brasil, Estados Unidos, África do Sul e França. Ambos organizados pela autora e editados pela Pallas. A pesquisa contemplou a aplicação de questionários junto a alunos dos cursos mais e menos concorridos das universidades visitadas e fez ainda o levantamento dos editais das 96 universidades estaduais e federais existentes então e que adotavam novas políticas para outros públicos-alvo. Os centros universitários e fundações de ensino superior não foram incluídos.
} 
controvérsia na época); e, em 2005, uma universidade estadual de São Paulo (Unicamp) pensa em acréscimo de pontos para alunos oriundos de escola pública com percentual para negros. Estas foram as universidades modelos para todas as outras que viriam a pensar em algum tipo de AA. E se eram poucas em 2005, em 2011 havia $70 \%$ das universidades públicas com algum tipo de AA.

Pode-se assim agrupar em três grandes grupos as políticas de AA adotadas nas universidades:

- Acréscimo de vagas, política pensada unicamente para populações indígenas;

- Cotas para negros, egressos de escolas públicas, deficientes e de baixa renda, modelo adotado pela maioria das universidades numa combinação variada desses critérios;

- Acréscimo de nota, adotado por várias universidades federais depois que a Unicamp o implantou.

Quanto ao impacto das políticas adotadas por cada universidade, as falas dos gestores entrevistados podem ser sintetizadas em seis pontos, e que ajudam a desmistificar os receios iniciais quanto à $\mathrm{AA}$ nas universidades públicas:

- Os alunos beneficiários de AA foram capazes de superar as deficiências acadêmicas trazidas de um ensino médio com menos recursos do que os alunos provenientes do vestibular universal em um período médio de dois anos, passando a ser disputados por professores para projetos de iniciação científica;

- A evasão escolar foi um pouco maior do que a dos alunos do vestibular tradicional, mas como lembraram os gestores, evasão se dá também pela dificuldade financeira de vários deles de permanecerem mais quatro anos apenas estudando;

- Os alunos de AA trouxeram para a universidade novas necessidades, inexistentes quando o quadro discente era mais homogêneo: alimentação, transporte e moradia não eram problema;

- Houve mudança na sociabilidade no campus e um processo pedagógico tanto para alunos quanto para professores, com a variedade de cor e classe inexistente anteriormente, tanto no seu aspecto positivo (aprendizado na convivência com outra classe, raça e etnia) quanto negativo (olhares sutis de preconceito e estranhamento);

- Mudança interna dos alunos de AA e para a família: percepção de que é possível estar numa universidade e encarar as dificuldades (afinal são alunos que já ultrapassaram várias barreiras anteriores) e representam a primeira geração em suas famílias a frequentarem o ensino superior; 
- O último impacto é bem interessante: são pensadas novas pautas de pesquisa que refletem questões sociais trazidas pelos novos alunos.

Não é fácil descrever esse processo, pois a mesma universidade podia adotar os três tipos de AA acima para público-alvo distinto. Mas o que se quer ressaltar aqui é que o debate ocorrido sobre a AA na universidade foi sendo assimilado por acadêmicos, juristas e políticos em duas dimensões principais: no nível macro, o amplo debate de vários anos, em especial nas universidades, na mídia ou organizações de militância negra ou de direitos humanos. Estavam sendo afinal debatidas questões antes incontestes, como o mérito no exame de vestibular e a harmonia racial nas relações sociais do país. Exemplo disso foi a decisão unânime do Supremo Tribunal Federal sobre a constitucionalidade das cotas para negros na UnB em 2012: na decisão dos onze juízes pode-se perceber que foram incorporados vários argumentos dos frames construídos ao longo da década. Sintetizando suas decisões, estas se pautaram na justiça racial, na existência de preconceito e discriminação, na reparação de injustiças passadas, na necessidade de integração social e na promoção da diversidade. Em outras palavras, nos frames construídos pelo intenso debate de dez anos.

No nível micro, as discussões ocorridas no meio acadêmico, em seminários e em várias outras instâncias da sociedade civil, acerca da "cota racial" explicam bem o o debate ocorrido nos Conselhos Universitários acerca da decisão entre a adoção de AA para escolas públicas ou AA para negros. Foi bastante ilustrativo para a dificuldade de se pensar na questão racial no Brasil na chave da desigualdade desse grupo. Ainda que a demanda por AA tenha partido dos movimentos negros, o que prevaleceu foi a cota social nas decisões dos vários conselhos, ficando as AA para negros como o terceiro grupo beneficiário, depois das escolas públicas e indígenas. Assim, o intenso debate sobre "cotas" para "negros" nas universidades públicas evidencia dois aspectos: a) a dificuldade de se considerar que a desigualdade da sociedade brasileira tenha cor; b) a crença de que os negros estariam contemplados em políticas mais amplas sem especificar a raça. É novamente a evitação da questão racial, resultando na busca de um discurso conciliador nos argumentos que prevaleceram nos debates dos conselhos universitários.

\section{Discurso conciliador no debate sobre AA}

A discussão sobre AA tem como princípio norteador a aceitação de políticas públicas que interfiram na estrutura desigual existente. Viu-se acima que os novos frames construídos na luta pela legitimação de se aplicar políticas desiguais para grupos estruturalmente desiguais encontram grande oposição e impacto em uma sociedade cujas bases foram construídas sobre profunda desigualdade social. Afinal, o Brasil sempre foi o país dos paradoxos, da ambigüidade, da convivência entre concepções de 
mundo opostas e que não provocaram grandes rupturas. Foi um país que proclamou uma república pelo alto, que resistiu ao fim da escravidão, que não soube pensar em direitos sociais universalizados (em especial a educação universalizada) para a construção de um projeto de nação que promovesse justiça social. Tampouco conseguiu se libertar de toda a herança originária do acordo injusto construído até a década de 1980: autoritarismo social (Vera Telles, 1994), "apartheid" social de classes que não se comunicam (Reis, 1998), hierarquias consolidadas em relações clientelistas (Carvalho, 1991) e paternalismo a mitigar os efeitos de tal arranjo (Velho, 1992).

A análise de Laclau sobre "significantes vazios" é muito oportuna para a compreensão da naturalização das desigualdades raciais e sociais. As ideologias da democracia racial, do mérito pessoal e da crença no desenvolvimento nacional do país do futuro foram essenciais para a manutenção de um acordo social pouco afeito a mudanças, no qual as desigualdades persistentes eram traduzidas ou na culpa pessoal pelo fracasso de sua integração social, ou na sua solução em um futuro impreciso. São frames formais, num processo metonímico do particular dimensionado como universal, de significantes vazios cultivados por grupos hegemônicos, que logram passar tais ideias como de interesse de toda a sociedade. É, como analisa Laclau, inspirado na tradição marxista da ideologia do interesse geral, a relação hegemônica de legitimação de discursos de grupos dominantes (2000;57): "it requires the production of tendentially empty signifiers which, while maintaining the incommensurability between universal and particulars, enables the latter to take up the representation of the former". Assim, conceitos como cidadania, justiça, igualdade, competência, direitos, dentre outros, são esvaziados de seus significados nos discursos hegemônicos, mas são poderosos para a obtenção da aquiescência geral ao acordo social perverso.

E a discussão empreendida aqui sobre AA no ensino superior é exemplar para se compreender as tensões originadas no debate universitário. Afinal, a sociedade brasileira sempre foi muito pouco afeita a conflitos: a cordialidade permeou a subalternidade, o paternalismo mitigou a desigualdade, e as relações hierárquicas funcionaram como grande mecanismo de controle para o surgimento de confrontos. Porque cada um sabia seu lugar, como analisou DaMatta (1993). Assim, a demanda por ação afirmativa nas universidades representou uma instância exemplar de questionamento de tal harmonia e dos significantes vazios. Como lembrou Joaquim Barbosa Gomes (2001), as políticas de AA trazem necessariamente acaloradas discussões, uma vez que a luta por maior igualdade se contrapõe aos interesses de outros na manutenção do status quo. Barbosa lembra ainda que a definição de direitos de cidadania na sua dimensão formal de igualdade tem-se revelado um "formidável fracasso" na construção de uma sociedade mais democrática.

Como visto na discussão anterior, predominou o discurso harmonizador na adoção de cotas sociais, quando a desigualdade racial ficou, mais uma vez, subsumida 
na desigualdade social, evidenciando bem o limite do debate. Nas palavras de um dos gestores entrevistados para definir a AA de corte racial ou social, ele afirma: "não foi a melhor medida, mas a medida possível".

\section{Considerações finais}

A análise feita acima registra o momento em que a adoção de políticas de AA nas universidades públicas dependia da decisão do Conselho Universitário de cada universidade. Foram dez anos de um processo gradual na implantação dos quatro tipos de AA, combinados de forma variada para atender a públicos-alvo específicos. Devido ao escopo do que foi apresentado, foi impossível relatar todas as nuances do processo. Mas a discussão realizada ao longo da década de 2000 motivou o Ministério da Educação do governo federal a pensar em políticas específicas de AA, em especial duas: o Programa Universidade para Todos (ProUni), de 2005, que incentivou universidades privadas a pensarem em AA em troca de isenção fiscal; e o Reuni, de 2007, que passou a aportar mais $20 \%$ do orçamento anual das universidades federais que pensassem em programas de inclusão. Essa é uma história que já teve um fim para as universidades federais: a ideia de acelerar o processo de inclusão no ensino superior foi ainda legitimada pela Lei Federal 12711/2012, que determinou a implantação de políticas de ação afirmativa nas universidades federais, que têm prazos graduais para pensar em políticas de inclusão para egressos de escolas públicas, 50\%, incluindo nesse percentual a diversidade étnica de cada estado. Também as universidades estaduais que resistiam à ideia de "cotas" na década de 2000, como a USP, estão hoje instadas a abrir seus espaços acadêmicos para alunos de outras cores e classe social.

Falava-se inicialmente na equação perversa da universidade pública brasileira no que se refere à seleção elitista de seu alunado. A análise feita acima procurou mostrar como a adoção de AA nas universidades públicas representou um momento virtuoso, quando houve a ação de movimentos sociais, de acadêmicos e políticas nas esferas governamentais em torno da legitimidade de se pensar em ação afirmativa para mitigar os efeitos da histórica desigualdade racial brasileira e da falta de acesso de grupos que nem sequer imaginavam ser possível a entrada na universidade.

Foi ressaltado aqui o processo em curso com a redemocratização do país, com a ação de movimentos sociais que questionavam o acordo societário consolidado até então; com o desconforto de vários professores universitários com a cor branca da universidade, em especial nos cursos de maior prestígio de cada universidade; com parte minoritária dos legislativos estaduais que pensavam em adoção de AA como remédio indispensável para acelerar a redução das desigualdades social e racial (ou para ganhar capital político); e com um executivo que trouxe a questão racial como 
norteador de políticas de governo. Exemplo mais marcante foi a criação da Secretaria Especial para a Promoção da Igualdade Racial (SEPPIR), em 2003, pelo então recémeleito presidente Lula.

A análise desse processo mostrou a formação de uma ação concertada na luta por uma universidade pública mais democrática e mais representativa da população brasileira, quando foram questionados os mecanismos perversos de reprodução de desigualdade social e racial no acesso ao ensino superior. Mostrou também a resistência de se lidar com a questão racial em si e ressaltou o discurso harmonizador, que foi consenso nos Conselhos Universitários, que pensou nas cotas sociais com um percentual pequeno e até mesmo residual para negros, quando este existia, subsumindo a questão racial na questão social.

Certamente pode-se argumentar que os negros são quase $70 \%$ da população pobre do país, mas como mostrou Nelson do Valle e Silva (2003), a mobilidade social dos brancos pobres foi sempre uma constante ao longo do século XX. Ao se recusarem a combater a desigualdade racial, prolonga-se o tempo de a universidade lograr refletir com mais clareza a configuração racial do país. Os discursos conciliadores, aqui traduzidos nas "cotas sociais", refletem a dificuldade de se lidar com a questão racial, pese todas as evidências dos dados.

Tais mudanças são sempre processos complexos e sujeitos a grande instabilidade devido a seu componente político no tocante a políticas públicas. Mas a aposta apresentada aqui é de que novos frames de justiça social/racial são essenciais no projeto de construção da democracia substantiva, ao desafiarem os significantes vazios predominantes. São enormes as dificuldades e a questão racial é uma das maiores delas.

\section{Bibliografia}

Alberti, Verena; Pereira, Amílcar. Histórias do movimento negro no Brasil. Rio de Janeiro: Pallas/FGV, 2007.

Avritzer, Leonardo. Cultura política, atores sociais e democratização. Revista Brasileira de Ciências Sociais, São Paulo, n. 28, 1995.

Barbosa, Joaquim. Ação afirmativa e princípio constitucional da igualdade. RJ: Renovar, 2001.

Bendix, Reinhard. Construção nacional e cidadania. São Paulo: EDUSP, 1996. 
Boschi, R. A arte da associação. São Paulo: Vértice, 1987.

Carvalho, José Murilo. Os Bestializados. São Paulo: Cia. Das Letras, 1991.

Costa, Sérgio. As cores de Ercília. Belo Horizonte: Editora UFMG., 2002.

DaMatta, Roberto. Relativizando. Rio de Janeiro: Rocco, 1993.

Dagnino, Evelina. Meanings of citizenship in Latin America. IDS, working paper, 2005.

Feres Jr, João. Políticas de Igualdade Racial no Ensino Superior. Cadernos do GEMAA, No. 5, 2014.

Fernandes, Florestan. A integração do negro na sociedade de classes. São Paulo: Editora Ática, 1978.

Fraser, Nancy. Justice Interrupts. New York: Routledge, 1997. \& Axel Honneth. Redistribution or recognition? A political-philosophical exchange.

New York: Verso, 2003.

Goffman, Erving. Frame Analysis: An essay on the Organization of Experiences. Cambridge, Mass: Harvard University Press, 1974.

Gohn, Maria da Glória. Movimentos sociais e redes de mobilização no Brasil contemporâneo. Petrópolis: Vozes, 2010.

Gonzalez, Lélia. O movimento negro na última década. In: Gonzalez, L. e Hasenbalg, C., Lugar de negro. Rio de Janeiro: Marco Zero, 1982.

Guimarães, Antônio Sérgio. Classes, raças e democracia. SP: Editora 34, 2002. . Racismo e anti-racismo no Brasil. SP: Editora 34, 1997.

Habermas, Jürgen. The Theory of communicative action. Boston: Beacon Press, 1987, vol. II.

Hasenbalg, C. e Valle e Silva, N. Relações raciais no Brasil Contemporâneo. RJ: Rio Fundo Ed. 1992.

. Origens e destinos. R.J: Topbooks, 2003. 
Heringer, Rosana. "Ação afirmativa e a promoção da igualdade racial no Brasil: o desafio da prática”. In: Paiva, Angela (org.) Ação afirmativa na universidade: reflexão sobre experiências concretas. RJ: Ed. PUC - Rio, 2004.

Henriques, Ricardo. Raça e gênero nos sistemas de ensino. Brasília: Unesco, 2001.

Laclau, Ernesto. Identity and Hegemony: The role of Universality in the Constitution of Political Logics. In: Butler, Laclau and Zizek, Contingency, Hegemony, Universality. London: Verso, 2000.

Nascimento, Abdias. O genocídio do negro brasileiro. Rio de Janeiro: Paz e Terra, 1978.

Paiva, Angela R (org.). Ação afirmativa em questão: Brasil, Estados Unidos, África do Sul e França. Rio de Janeiro: Pallas Editora, 2013.

. Entre dados e fatos: ação afirmativa nas universidades públicas brasileiras. Rio de Janeiro: Pallas Editora, 2010.

Paixão, M.; Carvano, M.L. (orgs.). Relatório anual das desigualdades raciais no Brasil. Rio de Janeiro: Garamond, 2008.

Petruccelli, J.L. Classificação racial e políticas de ação afirmativa nas universidades. Paiva (org.). Entre dados e fatos: ação afirmativa nas universidades públicas brasileiras. Rio de Janeiro: Pallas, 2010.

Reis, Elisa P. Pobreza, desigualdade e identidade política. Processos e escolhas. Rio de Janeiro: Contracapa, 1998.

Santos, Renato E. Racialidade e novas formas de ação social: o pré-vestibular para negros e carentes. In: Ações afirmativas. Políticas públicas contra as desigualdades raciais. Rio de Janeiro: DP\&A editora, 2003.

Souza, Jessé (org.). Multiculturalismo e racismo. Brasília: Paralelo 15, 1997.

Telles, Edward. Racismo à brasileira. Rio de Janeiro: Relume Dumará, 2003.

Telles, Vera S. Sociedade civil e a construção de espaços públicos. In: Dagnino (org.) Anos 90: Política e sociedade no Brasil. São Paulo: Ed. Brasiliense, 1994.

$\mathrm{B}^{\text {RASILIANA- Journal for Brazilian Studies. Vol. 6, n.2 (October, 2018). ISSN 2245-4373. }} 58$ 
Turner, Bryan. The Erosion of Citizenship. British Journal of Sociology, vol. 52, Issue 2, 2001.

Velho, Gilberto. Violência, reciprocidade e desigualdade: uma perspectiva antropológica. In: Cidadania e violência. Rio de janeiro: UFRJ/FGV, 1996.

Young, Iris. Polity and Group Difference: A Critique of the Ideal of Universal Citizenship. In: Beiner R. (ed.) Theorizing Citizenship. New York: SUNY, 1995. 